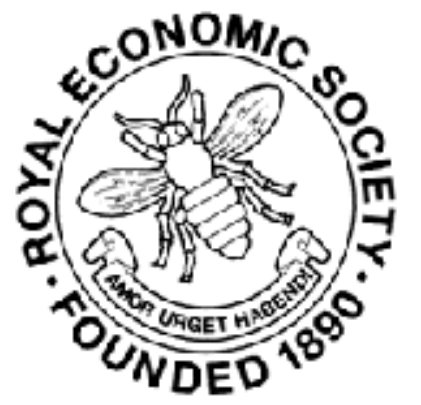

\title{
WILEY
}

The Interdependence of Different Sources of Demand and Supply in a Market

Author(s): A. C. Pigou

Source: The Economic Journal, Vol. 23, No. 89 (Mar., 1913), pp. 19-24

Published by: Wiley on behalf of the Royal Economic Society

Stable URL: http://www.jstor.org/stable/2222206

Accessed: 22-03-2016 13:21 UTC

Your use of the JSTOR archive indicates your acceptance of the Terms \& Conditions of Use, available at http://www.jstor.org/page/ info/about/policies/terms.jsp

JSTOR is a not-for-profit service that helps scholars, researchers, and students discover, use, and build upon a wide range of content in a trusted digital archive. We use information technology and tools to increase productivity and facilitate new forms of scholarship. For more information about JSTOR, please contact support@jstor.org. 


\section{THE INTERDEPENDENCE OF DIFFERENT SOURCES OF DEMAND AND SUPPLY IN A MARKET.}

$\S 1$. In the treatment of some economic problems it is sufficient to know the equations representing the demand schedule and the supply schedule of a market as a whole. Other problems, however, cannot be solved, unless we also know the relation that subsists between the aggregated demand or supply schedule and the demand or supply schedules, if such exist, of the separate sources of demand or supply, of which the market is compounded. For the purpose of elementary discussion it is usual to assume that an aggregated demand or supply schedule is always made up by the simple addition of a number of independent demand or supply schedules belonging to these separate sources. It is obvious that, when this assumption is made, the demand schedule of every source of demand can be represented by a plane curve, and the demand schedule of the market by a further curve obtained by the simple compounding of the curves representing the several sources; and that the same proposition holds good as regards supply. I wish to inquire in what circumstances the above assumption adequately conforms to the facts, and, when it does not so conform, what alternative assumption ought to be substituted for it.

$\S 2$. On the side of demand, the assumption seems to be fully warranted as regards commodities that are desired wholly for the direct satisfaction yielded by them, and not at all for the indirect satisfaction which their possession contributes through our thirst for reputation or distinction. On the side of supply, it seems to be fully warranted in respect of agriculture and the extractive industries, so far as these are carried on under conditions such that the part played by transportation, and, therewith, the rôle of "external economies" is unimportant. Furthermore, even when the assumption is not fully warranted, it may, nevertheless, be warranted for the limited purpose of the analysis of a particular group of problems-those, namely, which relate to disturbances of equilibrium so small that the aggregate output or consumption 
of the commodity affected is not greatly changed. Thus, as regards demand, it is reasonable to suppose that a considerable change in aggregate consumption is necessary to make people aware that any change in "commonness" has taken place, and, hence, to affect that part of anybody's demand which turns upon the reputation-value of the commodity. ${ }^{1}$ Similarly, as regards supply, a considerable change in aggregate output would have to come about before the general organisation and external economies of an industry were appreciably affected. Analytically, the point may be stated thus. Though the quantity of commodity demanded (or supplied) at a price $p$ in a market consisting of several sources cannot be approximately represented by the expression

$$
f_{1} p+f_{2} p+\ldots
$$

yet the change in the quantity demanded (or supplied) in that market in consequence of a small change of price $\Delta p$, can be approximately represented by the expression

$$
\Delta p\left\{f_{1}^{\prime} p+f_{2}^{\prime} p+\ldots\right\}
$$

In short, certain relevant variables may fairly be regarded as constants from the standpoint of small changes.

$\S 3$. In what has just been said the two most obvious influences, whose operation sometimes renders our fundamental assumption inapplicable to real life, have been implicitly indicated. As regards demand, the essential matter is that people do, in fact, desire many things, not merely for their own sake, but, in the main, on account of the reputation or distinction which the possession of them confers. Thus, J. S. Mill wrote: "When once the means of living have been obtained, the far greater part of the remaining labour and effort which takes place on the earth has for its object to acquire the respect or the favourable regard of mankind ; to be looked up to, or, at all events, not to be looked down upon by them. The industrial and commercial activities which advance civilisation, the frivolity, prodigality and selfish thirst of aggrandisement which retard it, flow equally from that source." ${ }^{2}$ To it, we may add, are due, in great measure, at once the desire for political success in England and business success in America, expenditure on personal adornment and on philanthropic work, the concealment of inventions for profit and the revealing of them for fame, ${ }^{3}$ the purchase of pictures for the home and the presentation of pictures to public galleries. The consequence of this fact from our present point of view is obvious. The quantity of a

1 Cf. my paper Some Remarks on Utility, Economic Jodrnac, Vol. xiii. p. 65.

2 Mill, Three Essays on Religion, p. 87. Cf. also Marshall, Principles of Economics, p. 162.

3 Cf. Chapman on American and English methods, Work and Wages, p. 41. 
distinction-bearing article that anyone demands at a given price depends, not merely on the price, but also on the extent to which it is "the thing" to buy that article, and thus, indirectly upon the quantity that people in general are buying. As regards supply, the essential matter is "external economies." Where circumstances are such that organisation and so forth can be much bettered when the aggregate scale of an industry is large than when it is small, the quantity of the commodity that anyone supplies at a given price depends, not merely on the price, but also on the quantity that people in general are supplying.

$\S 4$. In circumstances of the kind just described, it is evident that, though the demand (or supply) schedule of the market can be represented by a plane curve, the demand (or supply) schedules of the separate sources that make up the market cannot be so represented, and cannot be simply added together to constitute the aggregated demand (or supply) schedule. It, therefore, becomes necessary to inquire whether, in these cases, any other assumption of a reasonably simple nature can be employed, instead of the assumption of independent individual schedules with which we have hitherto worked. One such assumption readily suggests itself. It is to the effect that the price at which anybody demands (or supplies) a given quantity of commodity is made up by the addition of two parts, one depending on the quantity that the person in question himself demands (or supplies) and the other upon the quantity that the whole market collectively demands (or supplies). On this assumption, if $p$ be the price, $y$ the aggregate quantity demanded (or supplied), and $y_{r}$ the quantity demanded (or supplied) in the $r^{\text {th }}$ source,

$$
p=\phi y_{r}+\psi y \text {. }
$$

This formula is readily translated into the language of diagrams. The situation is the same as it would be if the commodity in question consisted of two physical constituents. For one of the constituents the market demand (or supply) curve is already in being, since the demand (or supply) price is known to depend in a definite manner on the aggregate amount. The other constituent is demanded (or supplied) by the several sources in such a way that the demand (or supply) price in each source depends solely upon the amount in that source. The market demand (or supply) curve for the second constituent is thus found by a simple addition of the curves for the several sources. We have only then to superimpose the curve for this second constituent upon that for the first to find the complete market curve for the commodity. The question we have now to ask is : Does the assumption just described represent the facts of life closely enough to 
be of practical value in any of those cases to which, as we have seen, the simple assumption proper to elementary discussion is inapplicable?

$\S 5$. I suggest that, on the side of supply, a field is available to which this assumption is not, indeed, perfectly adapted, but is sufficiently adapted to yield some fruitful results. In applying it to this field, we are, it must be granted, ignoring the fact that the effect on the supply price of the $r^{\text {th }}$ source of supply brought about by a given change in the output of that source may itself be different, according as the aggregate output of the whole market is large or small. Nevertheless, we are approaching much more nearly to real life than we are permitted to do by the method usually adopted. In particular, we are enabled to fit our analysis more closely to the difficult problem of increasing returns. On the ordinary method, a market schedule indicative of increasing returns must be made up of a number of schedules of independent sources, some, at least, of which also indicate increasing returns. A system of that kind, however, is necessarily in unstable equilibrium. Apart from obstructions due to the time element, to which Dr. Marshall has called attention, it would seem that one of the suppliers must drive all the others out of the market. In real life, however, as Professor Chapman has well emphasised, ${ }^{1}$ when the commodity is one whose production requires the help of subsidiary industries-a need attaching to all increasing return commodities-the separate sources are not really independent, and the presence of increasing returns in the market as a whole does not really imply its presence in the parts. In the phraseology employed above, the "constituent" of the commodity, which the sources produce independently, may obey the law of diminishing returns in all the sources for any aggregate of production, while the other "constituent" obeys the law of increasing returns rapidly enough to give the character of increasing returns to the supply schedule of the two constituents jointly. It is, thus, seen that the apparent conflict between mathematical analysis and experience, which has often perplexed the treatment of increasing returns, may disappear even without reference to the time element, if the assumptions from which the mathematical analysis starts are brought more nearly into conformity with the facts.

$\S 6$. For the sake of symmetry and formal niceness, it is much to be wished that the formula, which is thus seen to have value as regards complex supply, could also be fitted, without too serious violence to reality, to the facts of complex demand. Unfortunately, however, it must be confessed that this cannot be done.

1 Economic Journal, June, 1905, p. 191. 
First, in order that the formula may be applicable, the group of demanders making up a market must be so far homogeneous that the desire for the possession of a unit of commodity on account of its distinction-bearing quality, when a given aggregate of it is being consumed, has the same money value to each member of the group ; and this condition is obviously unlikely to be fulfilled. Secondly, the formula implies that the "part" of a man's demand price, which does not depend on the quantity of a commodity that he is purchasing, depends simply on the aggregate quantity that the market is purchasing. This condition would be fulfilled in respect of a commodity that was partly desired for the distinction given by being "in the swim" in general (e.g., top hats), or for that given by being out of the swim in general (e.g., diamonds). In fact, however, distinction is usually to be found, not in being in the swim in general, nor yet in being out of the swim in general, but in a combination of resemblance to certain persons and of difference from certain other persons. If the consumption of a commodity increases among those classes with whom I wish to be associated, my demand for it increases, but, if the consumption increases among those from whom I wish to separate myself, it decreases. Suppose, for example, that I am the mayor of a provincial town. In that case, if the Victorian Order becomes a more ordinary decoration for marquises, my desire for the decoration will be enhanced, but, if it becomes a more ordinary decoration for crossing-sweepers, I shall be tempted to regard its presentation to myself as an insult. Furthermore, both among the persons whom a man wishes to resemble, and among those from whom he wishes to separate himself, some are usualiy much more important to him than others. Thus, a given addition to the aggregate consumption of anything will affect my demand price for a $r^{\text {th }}$ unit of it quite differently if the addition is caused by extra purchases distributed over the public generally, or by extra purchases on the part of one of my heroes. Caracalla buys amber in honour of his mistress' hair; amber becomes a craze in Italy. A princess is lamed; court ladies limp. Majesty receives the "General" of a religious body; the inverted commas depreciative of his "generalship" disappear. When a royal personage condemns a barbarous fashion, the osprey yields to artificial flowers; just as, when insiders, or, perhaps, a single celebrated operator, bear or bull a stock, outsiders follow blindly. As Jevons observed long since, people go to places of recreation, music, or art, because other people of a class just superior to themselves are likely to be there : "Under the circumstances," he wrote, "it is, as it seems to me, a positive duty on the part of 
the middle and upper classes to frequent the well-conducted places of popular recreation to help to raise their tone. If, to induce them to do so, they must have royal or titled ladies to flock after, then I hope that those who enjoy the wealth and the privileges of this kingdom will bear in mind that they have duties also." 1 The principle involved is of wide application. It indicates the large extent to which leaders of society are able to direct the admiration and emulation of the public, and thus to encourage, as they will, literature, philanthropy, yacht-racing, or contributions to the party funds.

$\S 7$. To represent the complex conditions described in the preceding paragraph, the formula set out above is wholly inadequate. The demand of any $r^{\text {th }}$ source of demand in a market cannot be translated into any expression more simple than this :

$$
p=f_{r} y_{r}+\phi_{r} y_{1}+\psi_{r} y_{2} \ldots
$$

where the signs preceding the various terms may be either positive or negative, and where all that can be said in general is that each term (whether it is positive or negative) is likely to be larger, the larger is the argument contained in it. ${ }^{2}$ In cases where the influence exerted upon the demand schedule of source $A$ by a change in the consumption of source $B$ depends in part on the conditions prevailing in one or more of the other sources, even this formula is too simple, and it is necessary to fall back on the general expression :-

$$
p=\phi_{r}\left\{y_{r}, y_{1}, y_{2} \ldots\right\} \text {. }
$$

When the conditions are such that the demand schedule of the separate sources in a market must be represented by formulæ of this complex kind, problems, for the investigation of which it is necessary to go behind the demand schedule of the market as a whole, are still, theoretically, soluble; there are a sufficient number of equations to determine the unknowns. The solution, however, must needs be an algebraical solution, and no translation into the language of plane diagrams is possible. ${ }^{3}$

\section{A. C. Pigou}

1 Essays on Social Reform, p. 24.

2 The above formula must also be invoked on the side of supply when the output (at a given price) of a typical firm in one district is dependent in a much greater degree upon the organisation (as represented by output) of other firms in its immediate neighbourhood than upon that of other firms in distant parts of the world (cf. Macgregor, Industrial Combination, p. 27).

3 On the general problem discussed in the above paper the reader may be referred to the original article of Sir H. Cunynghame on "Some Improvement in Simple Geometrical Methods of Treating Exchange Values, Monopoly and Rent" (Economic JournaL, Vol. II. pp. 35 et seq.), to a review by Professor Edgeworth of the same author's work: "A Geometrical Political Economy" (ibid., Vol. XV. pp. 62 et seq.), and to an article by the present writer entitled: "Some Remarks on Utility" (ibid., Vol. XIII. pp. 59 et seq.). 